\title{
Influence of abiotic stress during soybean germination followed by recovery on the phenolic compounds of radicles and their antioxidant capacity
}

\author{
Sylwia Swigonska', Ryszard Amarowicz², Angelika Król ${ }^{1 *}$, Agnieszka Mostek1 , Anna Badowiec ${ }^{1}$, Stanisław \\ Weidner ${ }^{1}$ \\ 1 Department of Biochemistry, Faculty of Biology and Biotechnology, University of Warmia and Mazury in Olsztyn, M. Oczapowskiego 1A, 10-957 0lsztyn-Kortowo, Poland \\ 2 Division of Food Science, Institute of Animal Reproduction and Food Research of Polish Academy of Sciences, Tuwima 10, Box 55, 10-718 0lsztyn 5, Poland
}

\begin{abstract}
Abiotic stress factors are among the major causes of lower crop yields. It is known, that in response to cold and/or osmotic stress, crops activate various defense mechanisms, including morphological, physiological and metabolic adaptations. Secondary metabolism, especially phenolic compounds, seem to be an important factor of stress-induced metabolic re-engineering as their levels are alternated by abiotic stress in plants. Despite the fact, that the nature and function of phenolic compounds was already studied in various plant species, it is important to define tissue-specific changes induced by two most potent abiotic stressors - low temperature and decreased water potential. Moreover, in fields, the appearance of single stress is rather rare. Usually two or more factors are acting in parallel, which may potentially result in different effects. Therefore, the aim of this study was to analyze selected elements of secondary metabolism in roots of germinating soybean seeds under cold stress, osmotic stress and both stresses combined. In addition the effects of constant and persistent stress were compared to those induced by sudden and brief stress appearance, as well as after the post-stress recovery process. In the presented study standard methods for identification and quantification of phenolic acids and isoflavones were used and the antioxidant capacity of the radicle extracts was measured. The phenolic metabolism in plants was greatly intensified in response to cold and osmotic stress and remained at high level during the post-stress recovery. The amount and composition of both phenolic acids and identified isoflavones also changed in stress- and duration-dependent manner. This proves an important role of phenolic compounds in abiotic stress response of germinating soybean seeds and opens up new perspectives for further investigations.
\end{abstract}

Keywords: environmental stress; antioxidant capacity; phenolic compounds; phenolic acids; isoflavones

\section{Introduction}

It is believed that interactions of plants with their environment comprise biosynthesis of various secondary metabolites. Recent studies, have demonstrated that secondary metabolites, particularly phenolic compounds, perform important signaling and protective functions in plants. Environmental stresses often lead to intensive biosynthesis of phenolic compounds in plants and, as a consequence, they affect humans' and animals wellbeing [1-3]. It is noteworthy that the enhancement of plants' tolerance to adverse effects of environmental conditions would result in much higher yields obtained from the currently cultivated fields. Therefore, studies on basic mechanisms enabling plants to cope with environmental stresses are among high priority research areas in many countries [4].

\footnotetext{
*Corresponding author. Email: angelika.krol@uwm.edu.p Handling Editor: Grzegorz Jackowski
}

Previously published results suggest that plants respond to a variety of stress factors by increasing their capacity to scavenge reactive oxygen species [4-6]. Environmental stresses induce accumulation of phenolic compounds to protect tissues from damage caused by free radical-induced oxidative stress or to incorporate them into the cell wall as suberin or lignin [6-8]. Therefore analyzing both quantities and composition of phenolic compounds synthesized in response to stress factors is important for understanding the mechanism of stress response as well as for possible future engineering of crops to overproduce antioxidant phenolics. The unfavorable effect of low temperature and water potential on germination and development of industrial crops has been frequently discussed in scientific literature. However, there are fewer reports on different concomitant stresses of different durations, or research dealing with the post-stress recovery process.

Apart from inducing the general phenylpropanoid pathway, we hypothesize that abiotic stress must influence the composition of polyphenols, which may also reflect 
stress-induced metabolic re-engineering. Therefore the aim of this study was to examine soybean radicles in terms of quantitative and qualitative changes occurring in selected elements of the secondary metabolism as a result of cold stress, osmotic stress or a combination of both stresses in different durations. Another question examined was the effect of post-stress recovery on changes in the secondary metabolism of roots.

\section{Material and methods}

\section{Plant material and growth conditions}

The plant material used in this experiment consisted of cultivar Aldana common soybean seeds (Glycine max L.), purchased in Strzelce (Poland). The analyzed material was composed of roots isolated from germinating soybean seeds. Seeds were surface sterilized in $0.5 \%$ sodium hypochlorite for $20 \mathrm{~min}$, washed with sterilized water and placed on Petri dishes. The diagram of the experimental design is presented in Fig. 1. Control samples were germinated for 72 hours in $+25^{\circ} \mathrm{C} /$ water $(\mathrm{C} 72)$. To simulate conditions of cold and osmotic stress, seeds were divided into groups, germinating under following conditions: cold stress $-+10^{\circ} \mathrm{C} /$ water (CS72), osmotic stress $-+25^{\circ} \mathrm{C} /-0.2 \mathrm{MPa}(\mathrm{OS} 72)$ and cold stress combined with osmotic stress $-+10^{\circ} \mathrm{C} /-0.2 \mathrm{MPa}$ (COS72). Apart from constant and prolonged stresses, sudden and short-lasting stresses were applied. For this purpose, after germinating another batch of seeds for $48 \mathrm{~h}$ under optimal conditions $\left(+25^{\circ} \mathrm{C} /\right.$ water $\left.-\mathrm{C} 48\right)$ seeds were transferred for $24 \mathrm{~h}$ to the following conditions: cold stress $-+10^{\circ} \mathrm{C} /$ water (CS24), osmotic stress $-+25^{\circ} \mathrm{C} /-0.2 \mathrm{MPa}$ (OS24) and cold stress combined with osmotic stress $-+10^{\circ} \mathrm{C} /-0.2 \mathrm{MPa}$ (COS24). Additionally, seeds incubated under cold stress (CS24), osmotic stress (OS24) and combined cold and osmotic stress (COS24) underwent 24-h recovery in optimal conditions $\left(+25^{\circ} \mathrm{C} /\right.$ water $)$, as a result of which three more samples were obtained: CR, OR and COR (Fig. 1). In order to simulate osmotic stress of $-0.2 \mathrm{MPa}$, polyethylene glycol was used (molecular weight 8000 ; Sigma) at a concentration of $119.46 \mathrm{~g} / \mathrm{l}$ during germination at temp. $+25^{\circ} \mathrm{C}$ and 99.68 $\mathrm{g} / \mathrm{l}$ at $+10^{\circ} \mathrm{C}$. Once the set germination time was over, roots of germinated seeds were collected, immediately frozen in liquid nitrogen and kept in $-80^{\circ} \mathrm{C}$ for further analysis.

\section{Extract preparation}

Prior to the extraction frozen roots were homogenized and precisely weighed amount (10-20 mg) of homogenate was used as starting material. Phenolic compounds were extracted using $80 \%(\mathrm{v} / \mathrm{v})$ methanol at a solids to solvent ratio of $1: 10(\mathrm{~m} / \mathrm{v})$ at $50^{\circ} \mathrm{C}$ for $30 \mathrm{~min}$ [9]. The extraction was carried out in Erlenmayer flasks using a shaking water bath (Elpan 357, Wrocław, Poland). The extraction was repeated three times, the supernatants were filtrated and pooled, and the organic solvent was evaporated under vacuum at $40^{\circ} \mathrm{C}$ in a Büchi rotary evaporator; the remaining aqueous solution was lyophilized. Prepared extracts were stored at $-20^{\circ} \mathrm{C}$ until analyzed.

\section{Content of total phenolics}

The content of total phenolics in the crude extracts was estimated using Folin and Ciocalteu's phenol reagent [10]. (+)-Catechin was used as a standard.

\section{HPLC-PAD analysis of phenolic acids}

Phenolic acids (free and liberated from soluble glycosides) were isolated from the extracts according to the method previously described by Weidner et al. [11]. An aqueous suspension of the methanolic extract $(200 \mathrm{mg} / 20 \mathrm{ml})$ was adjusted to $\mathrm{pH} 2$ with $6 \mathrm{M} \mathrm{HCl}$, and free phenolic acids were

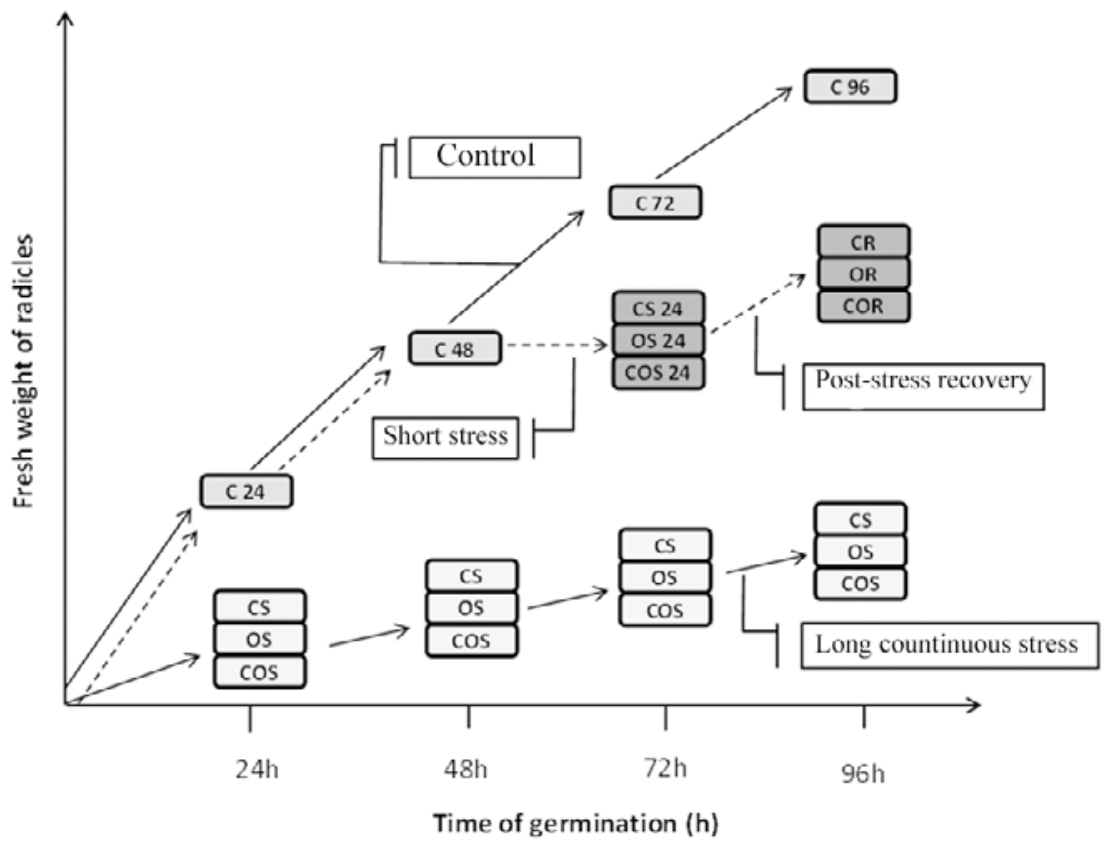

Fig. 1 Diagram of experimental design. Control samples were germinated for 72 hours in $+25^{\circ} \mathrm{C} /$ water $(\mathrm{C} 72)$. The study included three subsequent experiments: examining the effect of long and continuous stress (CS72 - cold stress, OS72 - osmotic stress, COS72 - combined stresses), short and rapid stress (CS24 - cold stress, OS24 - osmotic stress, COS24 - combined stresses) and post-stress recovery (CR recovery after cold stress, OR - recovery after osmotic stress, COR - recovery after combined stresses). Detailed description in the text. 
extracted five times into $20 \mathrm{ml}$ of diethyl ether using a separatory funnel. The ether extract was evaporated to dryness under vacuum at room temperature. The water solution was neutralized and then lyophilized. The residue was dissolved in $20 \mathrm{ml}$ of $2 \mathrm{M} \mathrm{NaOH}$ and hydrolyzed for $4 \mathrm{~h}$ under nitrogen atmosphere at room temperature. After acidification to $\mathrm{pH} 2$ using $6 \mathrm{M} \mathrm{HCl}$, phenolic acids released from soluble esters were extracted from the hydrolysate five times into $30 \mathrm{ml}$ of diethyl ether. Nine milliliters of $6 \mathrm{M} \mathrm{HCl}$ were added to the water solution and the solution was placed in nitrogen atmosphere and hydrolyzed for $1 \mathrm{~h}$ a boiling water bath. Phenolic acids released from soluble glycosides were separated from the hydrolysate five times into $45 \mathrm{ml}$ of diethyl ether. After ether evaporation, the dry residue was dissolved in $2 \mathrm{ml}$ of methanol and filtered through a $0.45 \mu \mathrm{m}$ nylon filter. The sample was injected onto an HPLC column. The same Shimadzu HPLC system was employed. The conditions of the separations were as follows: prepacked LUNA C18 column $(5 \mu \mathrm{m}, 4.6 \times 250 \mathrm{~mm}$; Phenomenex $)$; mobile phase water-acetonitrile-acetic acid (88:10:2, v/v/v) [11] flow rate of $1 \mathrm{ml} / \mathrm{min}$; injection volume of $20 \mu \mathrm{l}$; the detector was set at 280 and $320 \mathrm{~nm}$; oven temperature was $20^{\circ} \mathrm{C}$.

\section{Scavenging of the DPPH radical}

The scavenging effect of phenolics from the extracts was monitored as described by Amarowicz et al. [12]. A $0.1 \mathrm{ml}$ methanolic solution containing between $0.02-0.10 \mathrm{mg}$ of extract was mixed with $2 \mathrm{ml}$ of deionized water and then added to a methanolic solution of DPPH• (2,2-diphenyl1-picrylhydrazyl; $1 \mathrm{mM}, 0.25 \mathrm{ml}$ ). The mixture was vortexed for $1 \mathrm{~min}$, left to stand at room temperature for $20 \mathrm{~min}$, and absorbance of the solution was then measured at $517 \mathrm{~nm}$ with the spectrophotometer.

\section{Total antioxidant activity (TAA)}

The total antioxidant activity of the extracts was determined according to the Trolox equivalent antioxidant activity (TEAC) assay described by Re et al. [13]. TAA was expressed as mmol Trolox equivalent/g of extract.

\section{Qualitative and quantitative analysis of isoflavones}

Determinations of the content of isoflavones in tissues of roots of germinating soybean seeds were made according to the modified method described by Amarowicz et al. [14].

Isoflavones were extracted from roots with $80 \%$ methanol (in a 1:8 ratio), by shaking for 15 minutes at temp. $+75^{\circ} \mathrm{C}$. Cooled supernatants were filtered while the solid fraction underwent three more runs of extraction. The filtrates were then mixed and methanol evaporated in a vacuum rotary evaporator at temp. $+40^{\circ} \mathrm{C}$. The extracts were lyophilized to remove all water and stored until analyses at temp $-20^{\circ} \mathrm{C}$. Reverse phase high performance liquid chromatography (RP-HPLC) was used for separation of isoflavones from the analyzed extracts. Extracts of phenolic compounds were placed on a chromatographer's column filled with RP-18 gel (2-43 $\mu \mathrm{m}$; Merck) and then identification was performed with the HPLC method using a Shimadzu chromatographic system equipped with a C18 column $(5 \mu \mathrm{m}, 4.6 \times 250 \mathrm{~mm}$; Merck). The water-acetonitrile-acetic acid mixture (in a $88: 10: 2$ ration, v/v) was used as the stationary phase [15].
Each time, a sample of $20 \mu \mathrm{l}$ of an extract was placed on the column and the flow rate was $1 \mathrm{~cm}^{3} / \mathrm{min}$. Detection was performed at a wavelength of $254 \mathrm{~nm}$. Concentration of compounds in samples was determined with reference to standards obtained commercially (Extrasynthese, Genay Cedex, France).

\section{Statistical evaluation}

All experiments were conducted in three biological replicates (radicles isolated from 100 seeds) and two technical replicates for each sample. The presented values are shown as means \pm standard error of means (SEM). Statistically significant differences in the mean values were tested by student's $t$-test.

\section{Results}

\section{Changes in the total content of phenolic compounds}

The content of phenolic compounds in roots increased under constant and prolonged stresses, the total content of phenolic compounds in all examined samples significantly increased (Fig. 2a). It appeared that combination of cold and osmotic stress had the highest impact on the accumulation of phenolic compounds in roots.

Similar tendencies were observed in the subsequent experiment examining the effect of abrupt and short-lasting osmotic stresses (Fig. 2b). The total content of phenolic compounds increased significantly $(P<0.05)$ in all examined samples (Fig. 2b).

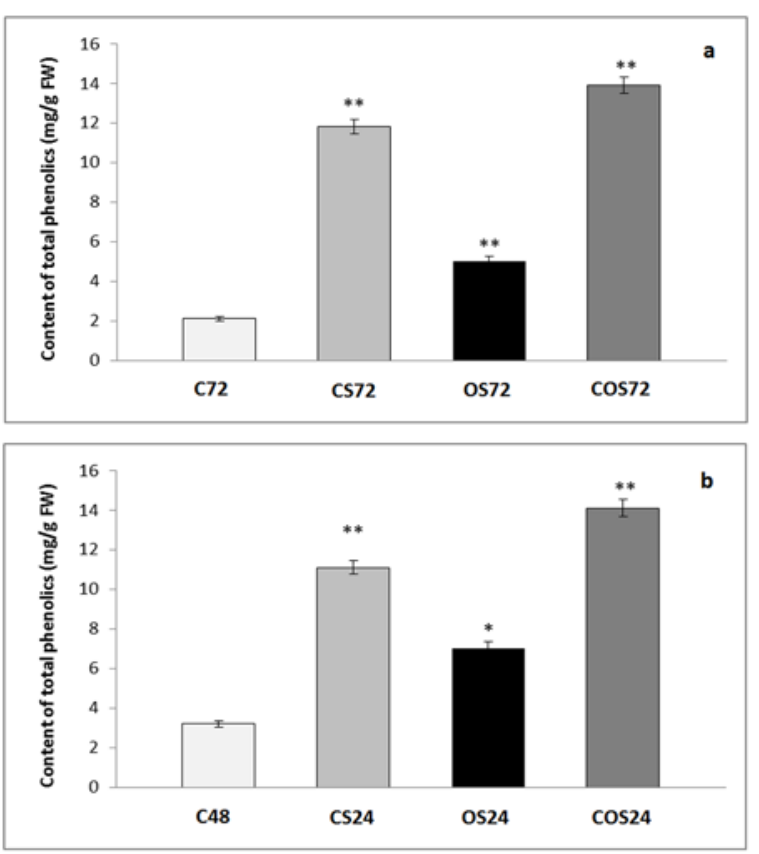

Fig. 2 Changes in the content of total phenolic compounds in soybean seeds germinating in optimal conditions and under: longterm continuous stress (a; C72 - control sample, CS72 - cold stress, OS72 - osmotic stress, COS72 - combined stresses), short-term rapid stress (b; C48 - control sample, CS24 - cold stress, OS24 osmotic stress, COS24 - combined stresses). Results are presented as means $\pm S E M$. Asterisks represent statistically significant differences at: $P<0.05\left(^{*}\right)$ or $P<0.01\left({ }^{* *}\right)$. 


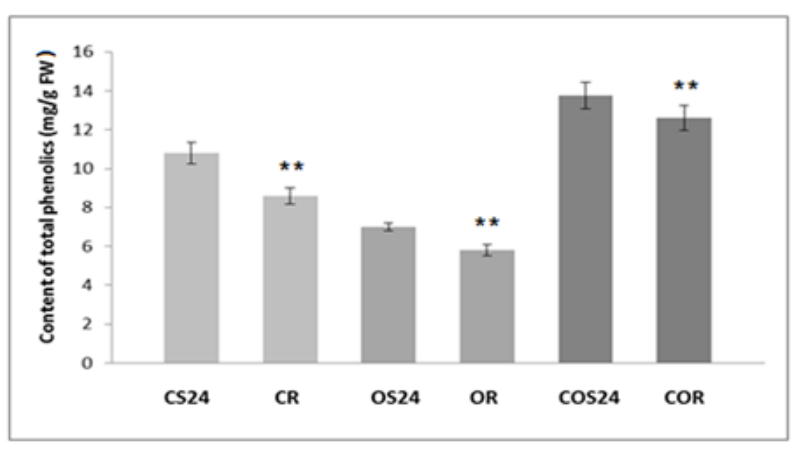

Fig. 3 Changes in the content of total phenolic compounds in soybean seeds germinating primarily for $48 \mathrm{~h}$ in optimal conditions, then for $24 \mathrm{~h}$ under short-term rapid stress conditions (CS24 - cold stress, OS24 - osmotic stress, COS24 - combined stresses) and finally transferred for $24 \mathrm{~h}$ to recovery: after cold stress (CR), after osmotic stress (OR), after cold stress combined with osmotic stress (COR). Results are presented as means \pm SEM. Asterisks represent statistically significant differences at: $\left.P<0.05{ }^{(}\right)$or $P<0.01\left(^{* *}\right)$.
Compared to the content of phenolic compounds in roots of seeds exposed to sudden and short-lasting stresses (serving as controls), the content of phenolic compounds after post-stress recovery decreased (Fig. 3).

\section{Changes in the composition of phenolic acids}

Five major phenolic acids were found in roots of germinating soybean seeds: vanillic, syringic, $\mathrm{p}$-coumaric, ferulic and sinapinic acid. Despite the fact that the method applied in the experiment enables extraction of free phenolic acids from plant material, our analysis revealed only ester- or glycoside-bound phenolic acids. Glycosided phenolic acids were detected only in roots subjected to short-term stress (CS24, OS24, COS24) and after post-short-term stress recovery (CR, OR, COR).

Root extracts from the control sample (C72) contained a dominant share of syringic and vanillic acid (Fig. 4). The content of sinapinic, p-coumaric and ferulic acids in the control was much lower. The prolonged cold stress (CS72) caused a decrease in the content of syringic, p-coumaric and ferulic acids whereas the amount of sinapinic acid increased and the content of vanillic acid did not change significantly (Fig. 4a). Under osmotic stress (OS72), a rapid increase in vanillic and sinapinic acids in roots was noticed. Amounts of syringic, p-coumaric and ferulic acids in roots decreased versus the
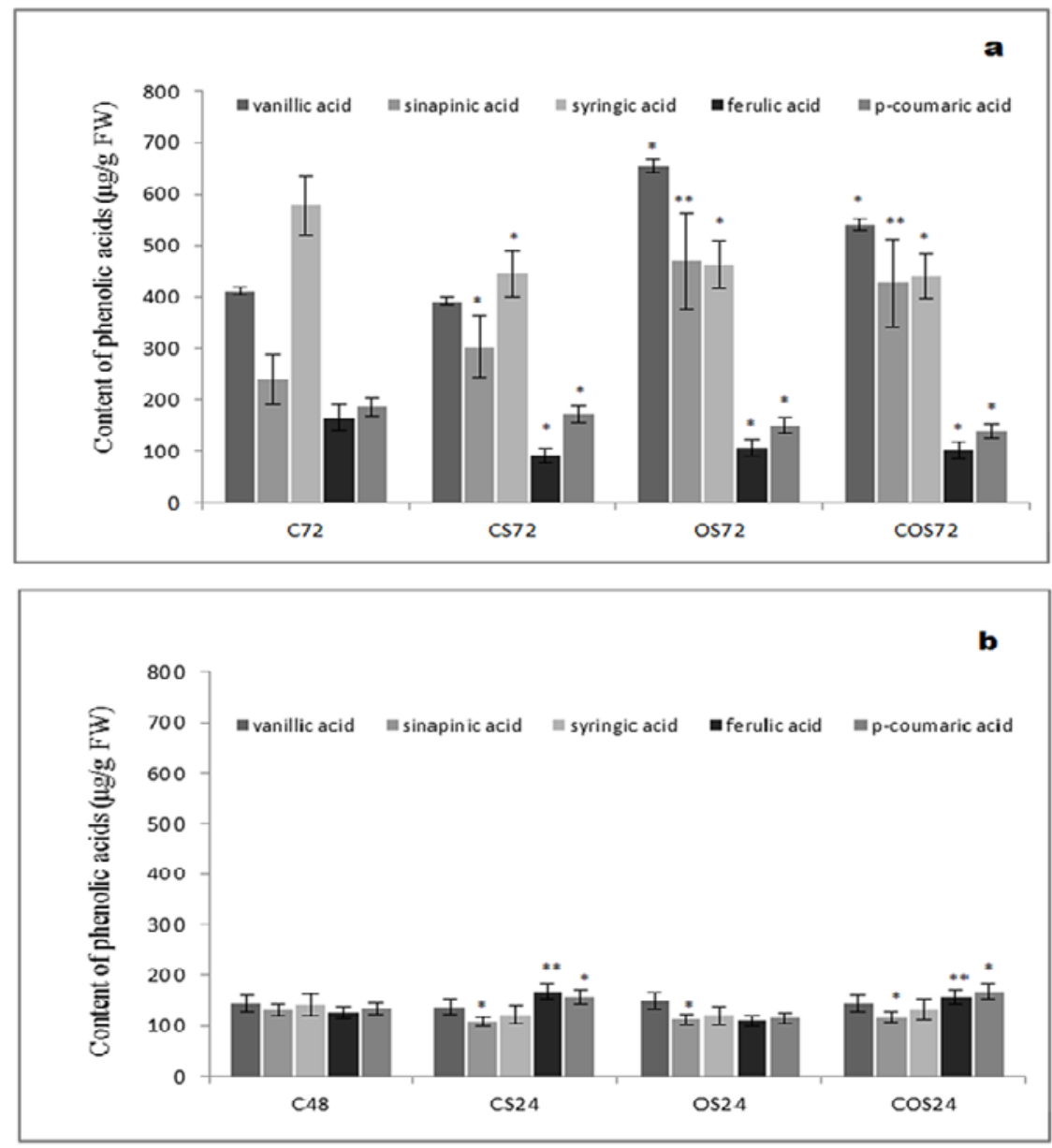

Fig. 4 Changes in the content of esterified phenolic acids in roots of soybean seeds germinating in optimal conditions (C72, C48) and subjected to: long-term continuous stress (a; CS72 - cold stress, OS72 - osmotic stress, COS72 - combined stresses) and short-term rapid stress (b; CS24 - cold stress, OS24 - osmotic stress, COS24 - combined stresses). Results are presented as means \pm SEM. Asterisks represent statistically significant differences at: $P<0.05\left({ }^{*}\right)$ or $P<0.01\left({ }^{*}\right)$. 
control sample. Under the combined stresses (COS72), the pool of phenolic acids isolated from roots contained higher amounts of vanillic and sinapinic acids (Fig. 4a).

After short-lasting cold stress (CS24), the content of ferulic and p-coumaric acids increased significantly relative to the control (C48), yet the amount of sinapinic acid was smaller and the content of vanillic and syringic acids did not change significantly (Fig. 4b). Short-lasting osmotic stress (OS24) resulted in lower amount of sinapinic acid. The content of vanillic, syringic, ferulic and p-coumaric acids did not differ significantly from the one found in the control sample (Fig. 4b). Roots of seeds exposed to short-lasting combined stress (COS24) were found to contain elevated amounts of ferulic and p-coumaric acids in the pool of the analyzed acids (Fig. 4b) in the content of sinapinic acid in roots however significantly decreased. Changes in the content vanillic and syringic acids were not statistically significant but demonstrated a decreasing tendency (Fig. 4b).

After post-cold recovery (CR) a strong increase in the content of vanillic sinapinic and syringic acids was observed, while the amounts of ferulic and p-coumaric acid in roots decreased (Fig. 5a). Recovery after osmotic stress (OR) also resulted in higher concentrations of vanillic, sinapinic and syringic acids. The amounts of ferulic and p-coumaric acids did not differ significantly (Fig. 5b). Similarly, allowing seeds to recover after the combined stresses (COR), their roots contained higher amounts of vanillic, syringic and sinapinic acids. The content of ferulic acid did not differ significantly compared to control. Interestingly, the content of p-coumaric acid in roots decreased. (Fig. 5c).
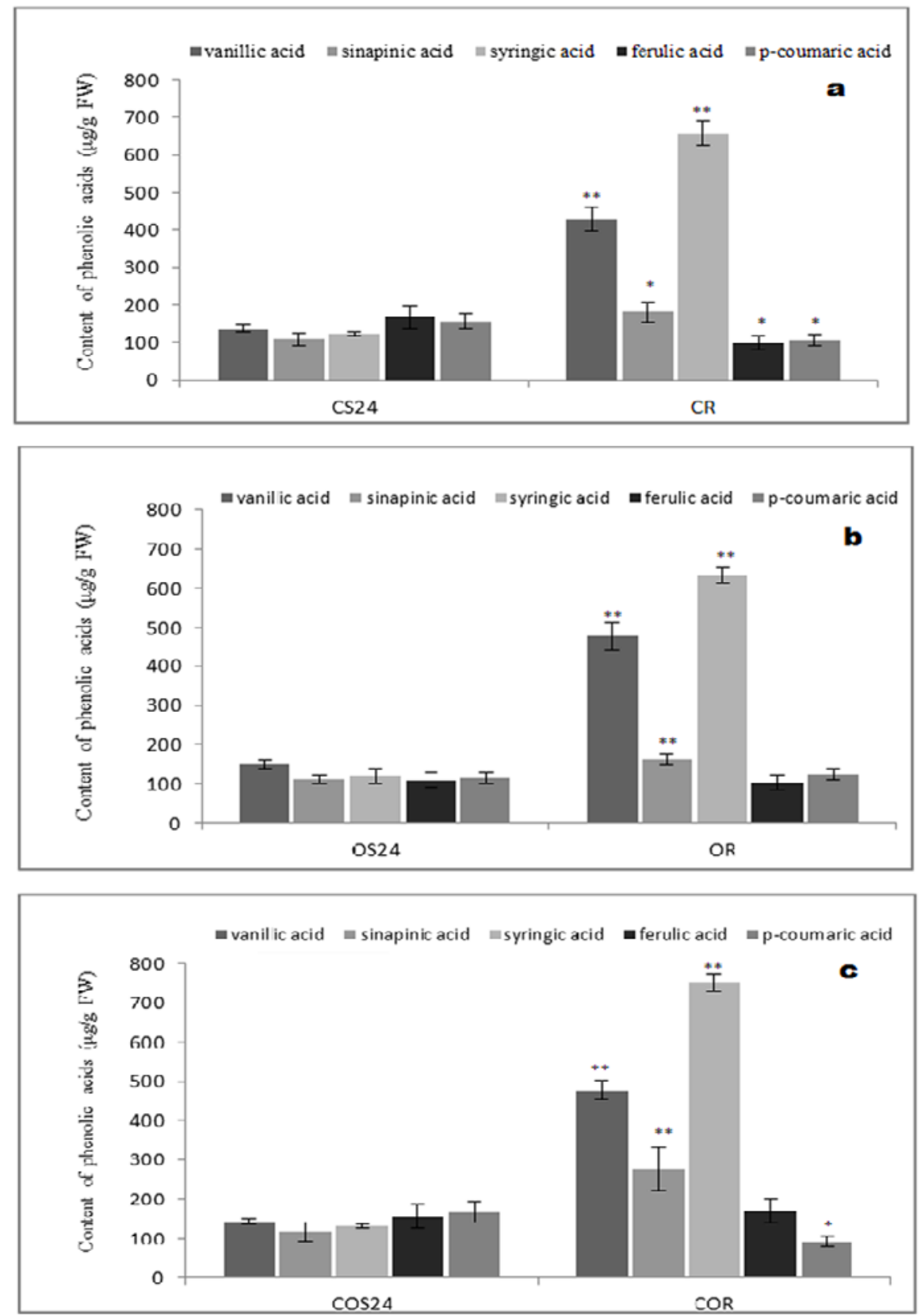

Fig. 5 Changes in the content of glycosided phenolic acids in roots of soybean seeds germinating primarily for $48 \mathrm{~h}$ in optimal conditions, then for $24 \mathrm{~h}$ under short-term rapid stress (CS24 - cold stress, OS24 - osmotic stress, COS24 - combined stresses) and finally transferred for $24 \mathrm{~h}$ to recovery after: cold stress (CR; a), osmotic stress (OR; b), and combined stresses (COR; c). Results are presented as means \pm SEM. Asterisks represent statistically significant differences at: $P<0.05\left({ }^{*}\right)$ or $P<0.01\left(^{* *}\right)$. 
Tab. 1 Changes in isoflavone content in roots of soybean seeds subjected to stress and post-stress recovery.

\begin{tabular}{|c|c|c|c|c|}
\hline \multirow[b]{2}{*}{ Sample } & \multicolumn{4}{|c|}{ Isoflavone content $(\mathrm{mg} / \mathrm{g} \mathrm{FW}) \pm S E M$} \\
\hline & Daidzein & Genistein & Daidzin & Genistin \\
\hline \multicolumn{5}{|c|}{ Long-term stress } \\
\hline C72 & $1.86 \pm 0.09$ & $1.94 \pm 0.03$ & $0.80 \pm 0.01$ & $0.20 \pm 0.04$ \\
\hline CS72 & $6.58 \pm 0.1^{\star \star}$ & $4.60 \pm 0.05^{\star *}$ & $1.38 \pm 0.05^{*}$ & $0.66 \pm 0.04^{*}$ \\
\hline OS72 & $5.35 \pm 0.12^{\star *}$ & $2.53 \pm 0.04^{*}$ & $1.22 \pm 0.08^{\star}$ & $0.79 \pm 0.07^{\star}$ \\
\hline COS72 & $10.94 \pm 0.25^{\star *}$ & $5.12 \pm 0.11^{* *}$ & $1.67 \pm 0.09^{*}$ & $1.22 \pm 0.1^{*}$ \\
\hline \multicolumn{5}{|c|}{ Short-term stress } \\
\hline $\mathrm{C} 48$ & $1.83 \pm 0.07$ & $1.86 \pm 0.06$ & $1.12 \pm 0.06$ & $0.27 \pm 0.01$ \\
\hline CS24 & $4.98 \pm 0.18^{* *}$ & $4.52 \pm 0.13^{\star *}$ & $1.14 \pm 0.29$ & $0.58 \pm 0.04^{*}$ \\
\hline OS24 & $3.95 \pm 0.06^{* *}$ & $3.51 \pm 0.08^{\star *}$ & $1.22 \pm 0.33$ & $0.55 \pm 0.07^{*}$ \\
\hline $\cos 24$ & $5.84 \pm 0.11^{\star *}$ & $4.77 \pm 0.17^{\star *}$ & $1.37 \pm 0.09^{*}$ & $0.73 \pm 0.03^{* *}$ \\
\hline \multicolumn{5}{|c|}{ Post-stress recovery } \\
\hline CR & $1.31 \pm 0.02^{\star *}$ & $2.55 \pm 0.13^{\star *}$ & $0.85 \pm 0.03^{\star}$ & $0.24 \pm 0.01^{\star}$ \\
\hline OR & $1.50 \pm 0.02^{* *}$ & $2.85 \pm 0.15^{* *}$ & $0.70 \pm 0.04^{*}$ & $0.19 \pm 0.01^{*}$ \\
\hline COR & $1.59 \pm 0.03^{* *}$ & $1.37 \pm 0.03^{* *}$ & $0.93 \pm 0.01^{*}$ & $0.22 \pm 0.02^{*}$ \\
\hline
\end{tabular}

Control samples were germinated for 72 hours in $+25^{\circ} \mathrm{C} /$ water $(\mathrm{C} 72)$. The study included three subsequent experiments: examining the effect of long and continuous stress (CS72 - cold stress, OS72 - osmotic stress, COS72 - combined stresses), short and rapid stress (CS24 - cold stress, OS24 - osmotic stress, COS24 - combined stresses) and post-stress recovery (CR - recovery after cold stress, OR - recovery after osmotic stress, COR - recovery after combined stresses). Results are presented as means $\pm S E M$. Asterisks represent statistically significant differences at: $P<0.05\left(^{*}\right)$ or $P<0.01\left(^{*}\right)$.

\section{Changes in the composition of isoflavones in seed roots}

Two isoflavones: genistein and daidzein and their glycoside derivatives: genistein and daidzin were identified in roots of soybean seeds (Tab. 1, Fig. 6). In the control sample (C72), contribution of daidzein and genistein was bigger that daidzin and genistin. After long-term cold stress (CS72), a significant increase in the content of all the analyzed isoflavones was observed. Similarly prolonged osmotic stress (OS72) and the combined stresses (COS72) affected the accumulation of isoflavones (Tab. 1). The rapid increase in the quantity of daidzein under the combined stresses is especially interesting.

Under the short-lasting cold stress (CS24), a statistically significant increase was observed in the content of daidzein, genistin and genistein. The concentration of daidzin in response to cold stress also tended to increase, but the differences were not statistically significant. Similar results were achieved for seeds subjected to osmotic stress (OS24) Under the short-lasting impact of both stresses, roots were observed to contain higher concentrations of all examined isoflavones (Tab. 1).

Post-stress recovery also induced changes in the root content of the analyzed isoflavones. As a result of the recovery after cold stress (CR), concentrations of all the examined isoflavones decreased significantly. During the recovery after osmotic stress (OR), quantities of all the isoflavones considerably declined. Concentrations of the analyzed isoflavones in samples after regeneration after combined stresses (COR) decreased, analogously to the previously discussed stress and recovery conditions (Tab. 1).

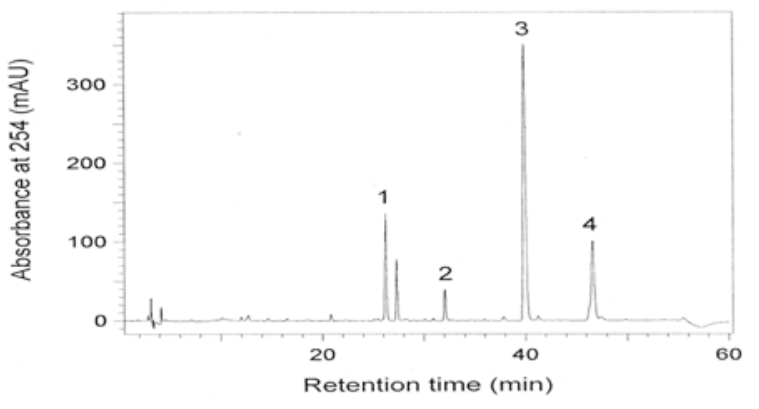

Fig. 6 HPLC chromatogram of isoflavones extracted from in soybean radicles: 1 - deidzin, 2 - genistin, 3 - deidzein, 4 - genistein.

\section{Changes in antioxidant properties of root extracts}

It has been shown that the biggest differences in absorbance between the control and samples submitted to stresses, resulting in the ability to scavenge the $\mathrm{DPPH}^{\cdot}$ free radical, occurred within the extract concentration range from 1 to $4 \mathrm{mg} / 100 \mu \mathrm{l}$ of the sample (Tab. 2). It is noteworthy that a depressed value of absorbance correlates with an improved capacity of extracts to reduce the $\mathrm{DPPH} \cdot$ free radical. By returning germinating seeds to optimal conditions their antioxidant capacity measured as the ability to scavenge $\mathrm{DPPH} \cdot$ radical raised compared to controls. In all the samples differences were statistically significant at the concentration of $4 \mathrm{mg} / 100 \mu \mathrm{l}$ (Tab. 2). 
Tab. 2 Capability of soybean root extracts to scavenge $\mathrm{DPPH}^{*}$ free radical after stress and post-stress recovery.

\begin{tabular}{|c|c|c|c|c|c|c|c|c|c|c|c|}
\hline \multirow{3}{*}{$\begin{array}{l}\text { Extract } \\
\text { concentration } \\
\text { (mg/100 ul } \\
\text { sample) }\end{array}$} & \multicolumn{11}{|c|}{ Absorbance at $\lambda=517 \mathrm{~nm} \pm S E M$} \\
\hline & \multicolumn{4}{|c|}{ Prolonged stress } & \multicolumn{4}{|c|}{ Short stress } & \multicolumn{3}{|c|}{ Post-stress recovery } \\
\hline & $\mathrm{C} 72$ & CS72 & OS72 & COS72 & $\mathrm{C} 48$ & CS24 & OS24 & $\cos 24$ & CR & OR & COR \\
\hline 0.5 & $1.70 \pm 0.02$ & $1.69 \pm 0.03$ & $1.71 \pm 0.04$ & $1.70 \pm 0.02$ & $1.77 \pm 0.06$ & $1.70 \pm 0.03$ & $1.70 \pm 0.07$ & $1.69 \pm 0.13$ & $1.70 \pm 0.15$ & $1.71 \pm 0.21$ & $1.70 \pm 0.14$ \\
\hline 1.0 & $1.54 \pm 0.09$ & $1.44 \pm 0.07^{*}$ & $1.62 \pm 0.11$ & $1.53 \pm 0.02^{*}$ & $1.59 \pm 0.05$ & $1.47 \pm 0.06$ & $1.50 \pm 0.09$ & $1.50 \pm 0.08^{* *}$ & $1.37 \pm 0.11$ & $1.49 \pm 0.09$ & $1.40 \pm 0.08$ \\
\hline 2.0 & $1.50 \pm 0.04$ & $1.35 \pm 0.05^{*}$ & $1.49 \pm 0.09$ & $1.38 \pm 0.09^{*}$ & $1.44 \pm 0.09$ & $1.30 \pm 0.03$ & $1.41 \pm 0.05$ & $1.37 \pm 0.05^{*}$ & $1.15 \pm 0.03^{*}$ & $1.32 \pm 0.11$ & $1.19 \pm 0.08$ \\
\hline 2.5 & $1.34 \pm 0.03$ & $1.20 \pm 0.05^{*}$ & $1.32 \pm 0.04^{*}$ & $1.21 \pm 0.07^{*}$ & $1.38 \pm 0.04$ & $1.10 \pm 0.01^{*}$ & $1.25 \pm 0.02^{*}$ & $1.19 \pm 0.02^{*}$ & $0.91 \pm 0.05$ & $1.24 \pm 0.09$ & $1.01 \pm 0.05$ \\
\hline 3.0 & $1.01 \pm 0.07$ & $0.98 \pm 0.03$ & $1.07 \pm 0.06$ & $1.00 \pm 0.04$ & $1.21 \pm 0.02$ & $0.95 \pm 0.09^{*}$ & $1.15 \pm 0.03^{*}$ & $1.00 \pm 0.03^{*}$ & $0.80 \pm 0.09$ & $1.14 \pm 0.06^{*}$ & $0.98 \pm 0.03^{*}$ \\
\hline 3.5 & $0.92 \pm 0.05$ & $0.89 \pm 0.05$ & $0.90 \pm 0.05$ & $0.84 \pm 0.07^{*}$ & $1.06 \pm 0.03$ & $0.84 \pm 0.08$ & $0.93 \pm 0.07$ & $0.82 \pm 0.02^{* *}$ & $0.54 \pm 0.04^{* *}$ & $0.84 \pm 0.04^{* *}$ & $0.76 \pm 0.03^{*}$ \\
\hline 4.0 & $0.88 \pm 0.02$ & $0.70 \pm 0.06^{*}$ & $0.77 \pm 0.05^{*}$ & $0.77 \pm 0.07^{\star}$ & $0.99 \pm 0.01$ & $0.80 \pm 0.02^{* *}$ & $0.77 \pm 0.01^{* *}$ & $0.70 \pm 0.02^{* *}$ & $0.48 \pm 0.05^{* *}$ & $0.67 \pm 0.03^{*}$ & $0.59 \pm 0.04^{* *}$ \\
\hline
\end{tabular}

Control samples were germinated for 72 hours in $+25^{\circ} \mathrm{C} /$ water $(\mathrm{C} 72)$. The study included three subsequent experiments: examining the effect of long and continuous stress (CS72 - cold stress, OS72 - osmotic stress, COS72 - combined stresses), short and rapid stress (CS24 - cold stress, OS24 - osmotic stress, COS24 - combined stresses) and post-stress recovery (CR - recovery after cold stress, OR - recovery after osmotic stress, COR - recovery after combined stresses). Results of absorbance at $\lambda=517 \mathrm{~nm}$ are presented as means \pm SEM. Asterisks represent statistically significant differences at: $P<0.05\left(^{\star}\right)$ or $P<0.01\left(^{\star *}\right)$.

The antioxidant capacity of extracts was also analyzed in terms of the ability to scavenge the $\mathrm{ABTS}^{+}$free radical (Fig. 7, Fig. 8). The free radical scavenging capacity was expressed in mmol of Trolox equivalent per gram of the analyzed extract. In samples exposed to prolonged stresses the antioxidant capacity was significantly higher than in the control (Fig. 7a), Similar results were obtained by analyzing the ability to scavenge $\mathrm{ABTS}^{+\cdot}$ in extracts from roots of seeds germinating under short-lasting stresses (Fig. 7b). No statistically significant differences were detected in the scavenging capacity of extracts from roots of seeds submitted to recovery after stresses (Fig. 8).
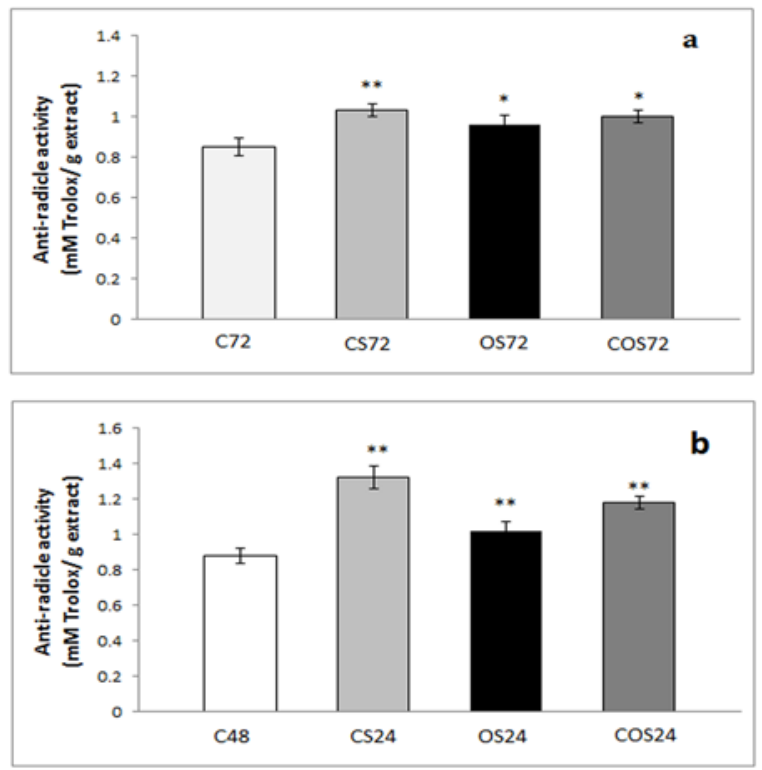

Fig. 7 Antioxidant activity of root extracts from soybean seeds germinating in optimal conditions (C72, C48) and long-term continuous stress (CS72 - cold stress, OS72 - osmotic stress, COS72 - combined stresses; a) and short-term rapid stress (CS24 - cold stress, OS24 - osmotic stress, COS24 - combined stresses; b). Results are presented as means $\pm S E M$. Asterisks represent statistically significant differences at: $P<0.05\left(^{*}\right)$ or $\left.P<0.01{ }^{* *}\right)$.

\section{Discussion}

Plants are constantly exposed to stresses in their natural habitats. Low temperatures and water deficit are the main limiting factors affecting crop yields worldwide. In this study, germinating soybean seeds were exposed to cold stress, osmotic stress and concomitant cold and osmotic stress, which in their strength were analogous to stresses naturally occurring in the moderate climate. These stresses, both brief and prolonged, cause various morphological, physiological and metabolic changes in tissues of germinating seeds, but the actual response to a given stress factor can differ depending on the duration of stress [16]. Chilling temperatures and osmotic stress affect the germination and growth of plants by disturbing most of cellular processes [17]. In our study both long- or short-lasting stress inhibited of the growth of soybean radicles (data not presented). Similar results were obtained in the earlier research [18-23]. During poststress recovery accelerated growth processes and more raid accumulation of root fresh matter were observed, which is analogous to the data reported by other authors $[16,24,25]$.

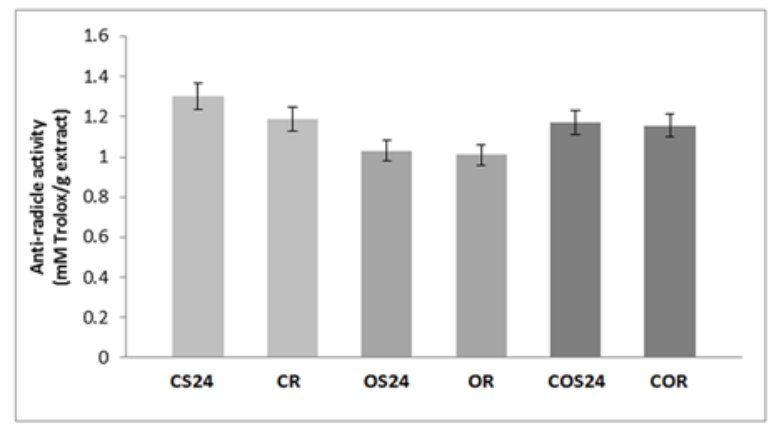

Fig. 8 Antioxidant activity of root extracts from soybean seeds germinating primarily for $48 \mathrm{~h}$ in optimal conditions, then for 24 h under short-term stress (CS24 - cold stress, OS24 - osmotic stress, COS24 - combined stresses) and finally transferred for $24 \mathrm{~h}$ to recovery after: cold stress (CR), osmotic stress (OR), cold stress combined with osmotic stress (COR). Results are presented as means \pm SEM. 
Our analysis of the total content of phenolics in roots demonstrated that the examined stresses (regardless of their duration) induced accumulation of phenolic compounds. These results are supported by the reports from other studies $[6,19,26,27]$. It is worth noticing that once the germinating seeds were transferred to optimal conditions, the total content of phenolics in roots declined, which suggests return to metabolic balance.

Plants produce a large variety of secondary products that contain a phenol group. Polyphenols are the most numerous group of natural antioxidants, highly varied in terms of structure, molecular weight or physical and chemical properties. In plants, they occur mostly as glycosides or esters [5]. Phenolic compounds in plants are said to play a key role as defense compounds counteracting negative effects of free radicals produced in stress conditions $[5,6,28]$. Thus, identification of the protective role of phenolic compounds, especially towards particular metabolites, requires monitoring.

Phenolic acids are an important link in the secondary metabolism of plants. They are a numerous group of derivatives of cinnamic acid (e.g. p-coumaric, ferulic, sinapinic acids) or benzoic acid (e.g. protocatechuic, gallic, vanillic acids). Their main function in plant defense mechanisms is antioxidant action [29], but they are also indicated (particularly vanillic and ferulic acids) as involved in the inhibition of cell elongation in growing organs [30]. Our results revealed five phenolic acids in soybean radicles, occurring only in the bound form, which stays in agreement with relevant references [31]. Vanillic and syringic acids dominated among the phenolic acids found in radicles under long and continuous stress. Intensive growth in the amount of vanillic and sinapinic acids in response to stress can be explained by their relatively high antioxidant capacity. Szwajgier et al. [31] demonstrated that these two acids are characterized by the highest free radical scavenging potential, and hence expected to protect roots from the adverse effects produced by free radicals [26]. Taken together this indicates that the stress-induced metabolic re-engineering involves not only the antioxidant activity but also a deceleration of cell growth.

Exposure of germinating seeds to sudden and brief stresses did not cause accumulation of vanillic and sinapinic acids, although the content of ferulic and p-coumaric acids in roots increased. Such modification in the composition of phenolic

\section{Acknowledgments}

The presented research was funded by the Department of Biology and Biotechnology (No. 528-0209.806), University of Warmia and Mazury in Olsztyn.

\section{Authors' contributions}

The following declarations about authors' contributions to the research have been made: general concept of the study: SW; experimental work: SS, AK, $\mathrm{AM}, \mathrm{RA}$; data collection and processing: AB; design of experiments and manuscript writting: SS; manuscript revision: RA, SW.

\section{References}

1. França SC, Roberto PG, Marins MA, Puga RD, Rodrigues A, Pereira JO. Biosynthesis of secondary metabolites in sugarcane. Genet Mol Biol. 2001;24(1-4):243-250. http://dx.doi.org/10.1590/ S1415-47572001000100032 acids may be caused by differences in the plants' response to continuous and persistent stresses versus sudden and transient ones. Ferulic and p-coumaric acids are the key links in the biosynthesis of lignin, whose elevated accumulation is observed under stress conditions [32]. Despite the post-stress recovery period, the content of vanillic, synaptic and syringic acids in soybean radicles were higher than in stress-treated samples. This may be explained by hypothesis, that accumulation of phenolic acids during post-stress recovery could be associated with the occurrence of a secondary oxidative stress after a period of low temperature impact $[26,33]$.

Our results confirmed close correlation between the content of phenolics and the antioxidant capacity of radicle extracts reported in previous studies [2,34,35]. It can be assumed that accumulation of phenolic compounds in roots of germinating seeds is used to minimize acute effects of secondary oxidative stress triggered by cold and osmotic stress. Increased antioxidant activity was also observed in extracts after post-stress recovery, which may be a result of the activation of the damage-repair system in tissues exposed to abiotic stress [36].

The content of all identified isoflavones increased in all stress-treated samples, which confirms previously published data $[26,33,37,38]$. Wu [39] demonstrated that soybean isoflavones show free radical scavenging potential, with aglycones (daidzein and genistein) being stronger scavengers than their glycoside conjugates (daizdin and genistin). On the other hand, the ability of isoflavones to reduce free radicals is much weaker than other phenolic compounds [40]. We hypothesize that accumulation of isoflavones is more likely due to synthesis of phytoalexins, hence daidzein and genistein serve as their precursors [41]. Enzymes of the isoflavone synthesis pathway may combine into multicomplexes with enzymes of the phenylpropanoid pathway [32,42-44], occurring in a cell loosely attached to the endoplasmic reticulum and connected to transmembrane proteins. Such complexes with enzymes mediating lignin biosynthesis have also been detected in soybean [45] and in Arabidopsis [41]. All this data confirms that the response of soybean radicles both to long and short lasting cold and osmotic stress, involves activation of phenylopropanoid pathways. However, mutual relationships between secondary metabolic pathways as well as mechanisms regulating stress defense require further investigation.

2. Oh MM, Carey EE, Rajashekar CB. Environmental stresses induce health-promoting phytochemicals in lettuce. Plant Physiol Biochem. 2009;47(7):578-583. http://dx.doi.org/10.1016/j.plaphy.2009.02.008

3. Zielińska-Dawidziak M, Siger A. Effect of elevated accumulation of iron in ferritin on the antioxidants content in soybean sprouts. Eur Food Res Technol. 2012;234(6):1005-1012. http://dx.doi.org/10.1007/ s00217-012-1706-y

4. Sharma P, Jha AB, Dubey RS, Pessarakli M. Reactive oxygen species, oxidative damage, and antioxidative defense mechanism in plants under stressful conditions. J Bot. 2012;2012:1-26. http://dx.doi. org/10.1155/2012/217037

5. Amarowicz R, Weidner S. Biological activity of grapevine phenolic compounds. In: Roubelakis-Angelakis KA, editor. Grapevine molecular physiology and biotechnology. Dordrecht: Springer Netherlands; 2009. p. 389-405. http://dx.doi.org/10.1007/978-90-481-2305-6 
6. Cheynier V, Sarni-Manchado P, Quidean S, editors. Recent advances in polyphenol research. Oxford: Wiley-Blackwell; 2012. (vol 3).

7. Chalker-Scott L, Fuchigami LH. The role of phenolic compounds in plant stress responses. In: $\mathrm{Li} \mathrm{PH}$, editor. Low temperature stress physiology in crops. Boca Raton, FL: CRC Press; 1989. p. 27-40.

8. Ippolito A, Nigro F, Lima G. Mechanism of resistance to Botrytis cinerea in wound of cured kiwifruits. Acta Hortic. 1997;444:719-724

9. Amarowicz R, Raabe B. Antioxidative activity of leguminous seed extracts evaluated by chemiluminescence methods. Z Naturforsch C. 1997;52:709-712.

10. Amarowicz R, Pegg RB, Rahimi-Moghaddam P, Barl B, Weil JA. Freeradical scavenging capacity and antioxidant activity of selected plant species from the Canadian prairies. Food Chem. 2004;84(4):551-562. http://dx.doi.org/10.1016/S0308-8146(03)00278-4

11. Weidner A, Amarowicz R, Karamać M, Frączek E. Changes in endogenous phenolic acids during development of Secale cereale caryopses and after dehydration treatment of unripe rye grains. Plant Physiol Biochem. 2000;38(7-8):595-602. http://dx.doi.org/10.1016/ S0981-9428(00)00774-9

12. Amarowicz R, Karamac M, Weidner S, Abe S, Shahidi F. Antioxidant activity of wheat caryopses and embryos extracts. J Food Lipids. 2002;9(3):201-210. http://dx.doi.org/10.1111/j.1745-4522.2002. tb00219.x

13. Re R, Pellegrini N, Proteggente A, Pannala A, Yang M, Rice-Evans C. Antioxidant activity applying an improved ABTS radical cation decolorization assay. Free Radic Biol Med. 1999;26(9-10):1231-1237. http://dx.doi.org/10.1016/S0891-5849(98)00315-3

14. Amarowicz R, Piskuła M, Honke J, Rudnicka B, Troszyńska A, Kozłowska H. Extraction of phenolic compounds from lentil seeds (Lens culinaris) with various solvents. Pol J Food Nutr Sci. 1995;4(3):53-62.

15. Amarowicz R, Weidner S. Content of phenolic acids in rye caryopses determined using DAD-HPLC method. Czech J Food Sci. 2001;19(6):201-205.

16. Uma S, Prasad TG, Kumar MU. Genetic variability in recovery growth and synthesis of stress proteins in response to polyethylene glycol and salt stress in finger millet. Ann Bot. 1995;76(1):43-49. http://dx.doi. org/10.1006/anbo.1995.1076

17. Raven PH. Biology of plants. 7th ed. New York, NY: W.H. Freeman; 2005.

18. Kosowska M, Frączek E, Amarowicz R, Karama M, Abe S, Weidner S. Water-deficit-induced changes in cytoskeleton-bound and other polysomal populations in embryonic tissue during triticale caryopsis germination. Acta Physiol Plant. 2004;26(1):67-74. http://dx.doi. org/10.1007/s11738-004-0046-3

19. Wróbel M, Karama M, Amarowicz R, Fr czek E, Weidner S. Metabolism of phenolic compounds in Vitis riparia seeds during stratification and during germination under optimal and low temperature stress conditions. Acta Physiol Plant. 2005;27(3):313-320. http://dx.doi. org/10.1007/s11738-005-0008-4

20. Costa França MG, Pham Thi AT, Pimentel C, Pereyra Rossiello RO, Zuily-Fodil Y, Laffray D. Differences in growth and water relations among Phaseolus vulgaris cultivars in response to induced drought stress. Env Exp Bot. 2000;43(3):227-237. http://dx.doi.org/10.1016/ S0098-8472(99)00060-X

21. Caruso A, Morabito D, Delmotte F, Kahlem G, Carpin S. Dehydrin induction during drought and osmotic stress in Populus. Plant Physiol Biochem. 2002;40(12):1033-1042. http://dx.doi.org/10.1016/ S0981-9428(02)01468-7

22. Ismail AM, Hall AE. Variation in traits associated with chilling tolerance during emergence in cowpea germplasm. Field Crops Res. 2002;77(2-3):99-113. http://dx.doi.org/10.1016/ S0378-4290(02)00059-X

23. Munns R. Comparative physiology of salt and water stress. Plant Cell Env. 2002;25(2):239-250. http://dx.doi. org/10.1046/j.0016-8025.2001.00808.x

24. Duncan RF, Hershey JW. Protein synthesis and protein phosphorylation during heat stress, recovery, and adaptation. J Cell Biol. 1989;109(4 pt 1):1467-1481.
25. Weidner S, Kordala E, Brosowska-Arendt W, Karamać M, Kosińska A, Amarowicz R. Phenolic compounds and properties of antioxidants in grapevine roots (Vitis vinifera L.) under low-temperature stress followed by recovery. Acta Soc Bot Pol. 2009;78(4):279-286. http:// dx.doi.org/10.5586/asbp.2009.036

26. Posmyk MM, Bailly C, Szafrańska K, Janas KM, Corbineau F. Antioxidant enzymes and isoflavonoids in chilled soybean [Glycine max (L.) Merr.] seedlings. J Plant Physiol. 2005;162(4):403-412. http:// dx.doi.org/10.1016/j.jplph.2004.08.004

27. Chung IM, Kim JJ, Lim JD, Yu CY, Kim SH, Hahn SJ. Comparison of resveratrol, SOD activity, phenolic compounds and free amino acids in Rehmannia glutinosa under temperature and water stress. Env Exp Bot. 2006;56(1):44-53. http://dx.doi.org/10.1016/j.envexpbot.2005.01.001

28. Solecka D. Role of phenylpropanoid compounds in plant responses to different stress factors. Acta Physiol Plant. 1997;19(3):257-268. http://dx.doi.org/10.1007/s11738-997-0001-1

29. Karamać M, Kosińska A, Pegg RB. Comparison of radical-scavenging activities for selected phenolic acids. Pol J Food Nutr Sci. 2005;14(2):165-169.

30. Dixon RA, Paiva NL. Stress-induced phenylpropanoid metabolism Plant Cell. 1995;7(7):1085-1097. http://dx.doi.org/10.1105/tpc.7.7.1085

31. Szwajgier D, Pielecki J, Targoński Z. Antioxidant activities of cinnamic and benzoic acid derivatives. Acta Sci Pol Technol Aliment. 2005;4(2):129-142.

32. Dixon RA, Achnine L, Kota P, Liu CJ, Reddy MSS, Wang L. The phenylpropanoid pathway and plant defence - a genomics perspective. Mol Plant Pathol. 2002;3(5):371-390. http://dx.doi. org/10.1046/j.1364-3703.2002.00131.x

33. Janas KM, Cvikrová M, Pałagiewicz A, Szafranska K, Posmyk MM. Constitutive elevated accumulation of phenylpropanoids in soybean roots at low temperature. Plant Sci. 2002;163(2):369-373. http://dx.doi. org/10.1016/S0168-9452(02)00136-X

34. Naczk M, Shahidi F. Phenolics in cereals, fruits and vegetables: occurrence, extraction and analysis. J Pharm Biomed Anal. 2006;41(5):15231542. http://dx.doi.org/10.1016/j.jpba.2006.04.002

35. López-Amorós ML, Hernández T, Estrella I. Effect of germination on legume phenolic compounds and their antioxidant activity. J Food Compos Anal. 2006;19(4):277-283. http://dx.doi.org/10.1016/j. jfca.2004.06.012

36. Prasad TK. Mechanisms of chilling-induced oxidative stress injury and tolerance in developing maize seedlings: changes in antioxidant system, oxidation of proteins and lipids, and protease activities. Plant J. 1996;10(6):1017-1026. http://dx.doi. org/10.1046/j.1365-313X.1996.10061017.x

37. Graham TL, Graham MY. Signaling in soybean phenylpropanoid responses (dissection of primary, secondary, and conditioning effects of light, wounding, and elicitor treatments). Plant Physiol. 1996;110(4):1123-1133. http://dx.doi.org/10.1104/pp.110.4.1123

38. Piślewska M, Bednarek P, Stobiecki M, Zielińska M, Wojtaszek P. Cell wall-associated isoflavonoids and $\beta$-glucosidase activity in Lupinus albus plants responding to environmental stimuli. Plant Cell Env. 2002;25(1):20-40. http://dx.doi.org/10.1046/j.0016-8025.2001.00806.x

39. Wu Q. Purification and antioxidant activities of soybean isoflavones [Master thesis]. Baton Rouge, LA: Departament of Food Science, Louisiana State University; 2003.

40. Lee CH, Yang L, Xu JZ, Yeung SYV, Huang Y, Chen ZY. Relative antioxidant activity of soybean isoflavones and their glycosides. Food Chem. 2005;90(4):735-741. http://dx.doi.org/10.1016/j.foodchem.2004.04.034

41. Yu O, Jung W, Shi J, Croes RA, Fader GM, McGonigle B, et al. Production of the isoflavones genistein and daidzein in non-legume dicot and monocot tissues. Plant Physiol. 2000;124(2):781-794. http://dx.doi. org/10.1104/pp.124.2.781

42. Dixon RA, Harrison MJ, Paiva NL. The isoflavonoid phytoalexin pathway: from enzymes to genes to transcription factors. Physio Plant. 1995;93(2):385-392. http://dx.doi.org/10.1111/j.1399-3054.1995. tb02243.x

43. Dixon RA, Summer LW. Legume natural products: understanding and manipulating complex pathways for human and animal health. Plant Physiol. 2003;131(3):878-885. http://dx.doi.org/10.1104/pp.102.017319 
44. Winkel-Shirley B. Flavonoid biosynthesis. a colorful model for genetics, biochemistry, cell biology, and biotechnology. Plant Physiol. 2001;126(2):485-493. http://dx.doi.org/10.1104/pp.126.2.485
45. Rawel HM, Czajka D, Rohn S, Kroll J. Interactions of different phenolic acids and flavonoids with soy proteins. Int J Biol Macromol. 2002;30(34):137-150. http://dx.doi.org/10.1016/S0141-8130(02)00016-8 